\title{
Developing a Parenting Training Model of Character Education for Young Learners from Poor Families by Using Transformative Learning Approach
}

\author{
Ach. Rasyad ${ }^{1}$ \\ ${ }^{1}$ Faculty of Education, Universitas Negeri Malang, East Java, Indonesia \\ Correspondence: Ach. Rasyad, Faculty of Education, Universitas Negeri Malang, J1. Semarang 5 Malang, East \\ Java, Indonesia. E-mail: rasyadplsum@yahoo.co.id
}

Received: February 5, 2015 Accepted: March 16, 2015 Online Published: July 27, 2015

doi:10.5539/ies.v8n8p50 URL: http://dx.doi.org/10.5539/ies.v8n8p50

\begin{abstract}
This research is aiming at developing a parenting training model using a character education for young learners from the poor families. The data obtained were qualitative data drawn from open answers and Focus Group Discussion. The data were analyzed by using domain analysis and taxonomy. The research findings showed that there were some problems faced by parents in applying character education in their family environment; parents should be the one who become the role model for their children; to apply the character education to their children, parents have to join parenting training; the training expected by parents is the practical understanding training; identification of parents' understanding and training needs make a prototype of parenting training.
\end{abstract}

Keywords: training model, parenting, transformative learning, character education, young learners, the poor families

\section{Introduction}

Poor families are a community which is commonly abandoned and the analysis towards a character education of children from poor families is not much. Thus, the character education of children from poor families deserves to get a special attention and the development of the parenting training model of character education in poor families is expected to be a strategic solution to safe the young generation's characters.

This research is a caring action for the poor families as they are the marginal community. The majority of Indonesian people are living in poverty, but the economy policy in the national development program has not stood for them yet. This research is aiming at describing the role and function of parents as role models for their children. Other objectives of the research are describing a character education that should be done by parents to their children as well as conducting a parenting training model to make a prototype of parenting training in a family.

Baumrind (2006) states that there are three parenting methods applied by most parents to their children, i.e. authoritarian, authoritative, and permissive. The three parenting methods give a significant effect to the children's character. Moreover, there are also some factors which affect the parenting methods chosen by parents (Fanning, 2007; Gupta, 2008). They are life experience, value system orientation, and social, culture, and economy aspects. A parenting training is one of outside school education programs. Therefore, its development should refer to the outside school education training programs. Kamil (2010) says that one of the training models is a training as media to empower people. To be highlighted this kind of training aims at improving the people's skill so that they can be more professional in performing their job. Marzuki (2009) also states that the empowerment means giving authority to somebody because they do not have enough skill in a particular field. The training program should contain some aspects, such as trainers, trainees, training process, and training materials. Besides, from the theoretical side, the program should be able to implement theories and behavioristic approach (Moedzakir, 2010).

The transformative approach is applied because it is a part of adult education (Jarvis, 2004). It means that the approach is effective when it is applied to adults. This research is meant to parents from poor families, so it is expected that the approach can trigger the parents to change their perception significantly. The transformative approach in the adult education is the latest approach and it is the most-observed approach in the adult education 
(Taylor, 2008). This approach is an effective and efficient breakthrough to change the perception and awareness of parents. In a difficult situation, parents would tend to make a change within themselves (Mezirow, 2003).

Literally, characters mean mental qualities. Characters can also mean psychological nature, habit, personality, and morality which distinguish one person to another. Characterized means having good temper and good personality (Aziz, 2011). The character education is an attempt to build a whole and essential personality for an individual and community. Like applying a parenting method, parents are possible to build their children's characters by giving examples of attitude, action, and words (Wibowo, 2013).

\section{Method}

To develop or make a training model product, the researcher conducted a development research which used a procedural model. The procedural model is a descriptive model, which used particular steps to produce a product (State University of Malang, 2010, p. 37). The procedural model was adapted from the research and development model form Borg and Gall (2005) as well as procedural model developed by McKenny (2001).

This research took place in Malang city and regency. The subject of the research was the householders from 54 poor families in the urban, suburban, and village areas. Malang city and regency were chosen because they were the most densely populated area in East Java and they had a lot of poor families. Furthermore, their jobs were mostly labors, trash pickers, and farm workers.

The data obtained were qualitative data drawn from open answer and FGD. The data was analyzed by using an analysis proposed by Spradley, which were domain and taxonomic analysis. To meet the objective of this research, the researcher did an exploration study to get a complete description about the needs of parenting training model of the character education for children from the poor family as well as the prototype draft making.

The sample was taken by using non-probability sampling, in which there was no opportunity for all population members to be samples. In this non-probability sampling, the kind of samples used was the purposive sampling, in which the description of each area was taken from three kelurahan or villages. Then, from each kelurahan or village, six poor families were taken. The information for the research was collected from comprehensive interview and an interview guideline was developed (the interview guideline is attached). This was needed to avoid the illiterates parents become the samples. As an efficiency consideration, the interview was done in a Focused Group Discussion (FGD). For every area, the chosen householders were invited to the particular place. In addition, the researcher also conducted an observation to get the additional information such as the social and culture, and economy conditions as well as the potential of the family environment.

\section{Results}

Parents as "teachers" at home play the role of catching clues of the unsuccessful learning result so that they can solve the problem as soon as possible (Cranton, 2006). To stabilize the character education to their children, parents should comprehensively understand the character education itself. The comprehensive understanding can be done through a parenting training. To synchronize the objective, schools should be one which had the idea of the parenting training for parents. The parenting training model that is expected by most parents is a kind of training that is more practical, not too much theories in it. The training design that is expected is a participatory approach so that the enrichment program for parenting training model can be reached.

Some examples of parenting activities are parents gathering facilitated by schools, parents involvement in the children's activity, parents involvement in the school activity, parents-class (parents are asked to position themselves as children so that they can understand them more), parents-day (parents are invited to play and join the children's activities at school), parents-guide (parents are guided to teach their young children), training for children companion which is conducted by inviting parents, and some other activities that can be developed based on the needs.

The domain and taxonomic analysis were used in this research. The domain analysis was carried out to get the general and relative views of the characteristic of the parenting training. This was done by grouping the answers into categories. The categories were made based on the similarity of the responds towards particular questions. The taxonomic analysis was used to get the detail and comprehensive information about certain category (domain). In the taxonomic analysis, the focus was limitedly set on the particular domain. It was useful to describe or explain phenomenon that became the main target in the research.

To make the prototype of parenting training, it was necessary to do some identifications, i.e. parents' understanding towards the parenting materials, learning process, strategies, media, the expected result, parents' learning needs, and the concern as well as the plan of the parenting training program. Next, it was the step of describing the training strategies that were applied. The third step was exploring which aimed at identifying the 
strength and weakness of the designed parenting training model. The last step was analyzing the data descriptively by using qualitative analysis.

The prototype of the parenting training model is showed in Figure 1.

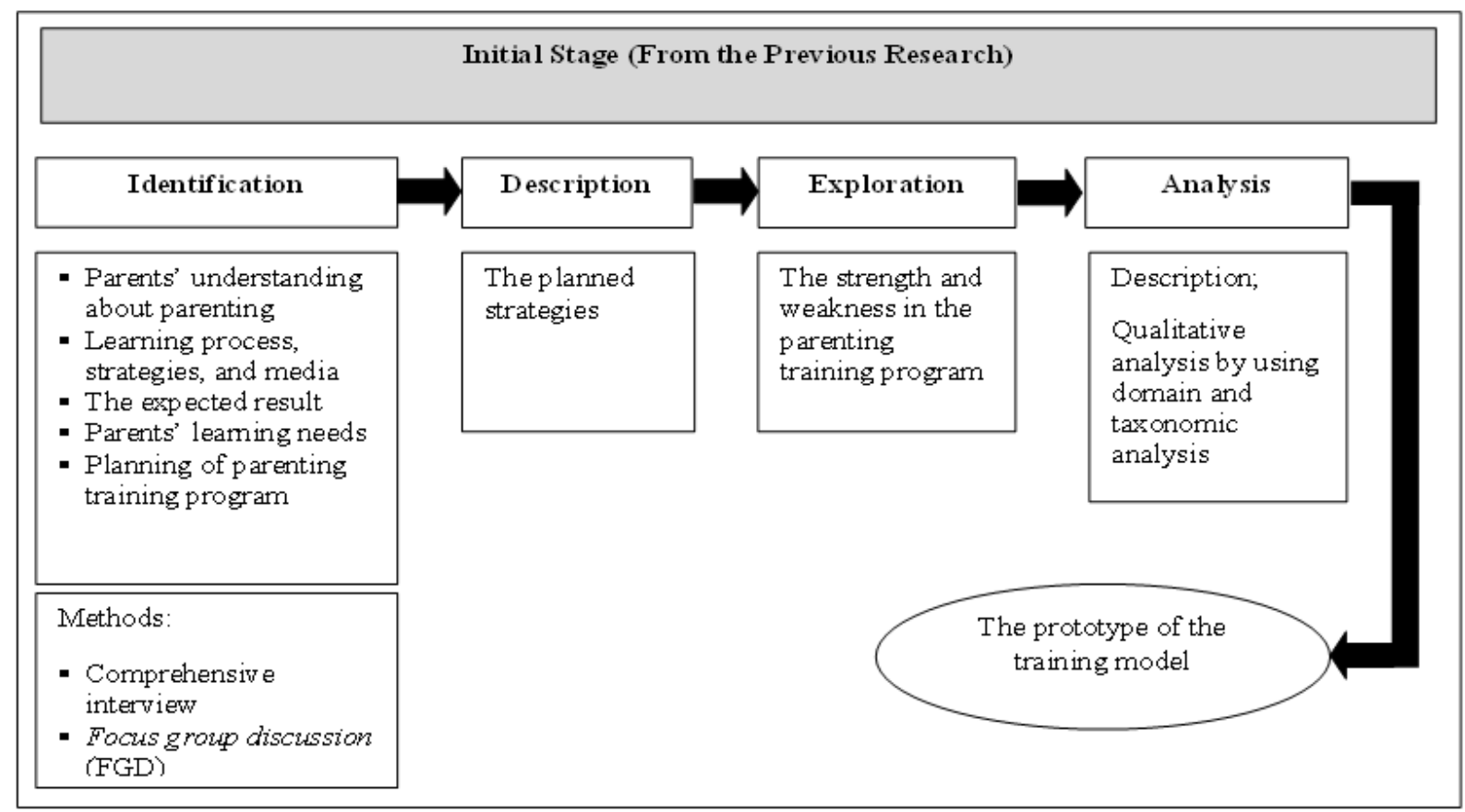

Figure 1. The prototype of parenting training model by using transformative learning approach for the poor family

The initial stage was identification which included (1) giving understanding to parents about the parenting materials, carrying out the learning process, setting strategies and media suitable for the poor families, checking the result, identifying the learning needs of the parents, and identifying the concern and plans of the parenting training program. In this stage, the method used was comprehensive interview, Focus Group Discussion (FGD), and observation. (2) The initial data gained from the field observation were described into a training strategy. (3) In the exploration stage, checking was done to identify the strength and weakness of the parenting training program. (4) The last stage was analyzing all the data qualitatively.

In applying the parenting training curriculum, detailed learning system, application for schools, and training materials for parents were ultimately needed. Besides, mentoring and training for parents were also the other things to be highlighted. This training was designed to meet the goal of character education for parents with low economy background. In the midst of the economy problem, it was expected that parents still had time to pay attention to their children and teach them some values. The curriculum of the parenting training program was shown in the Figure 2. 


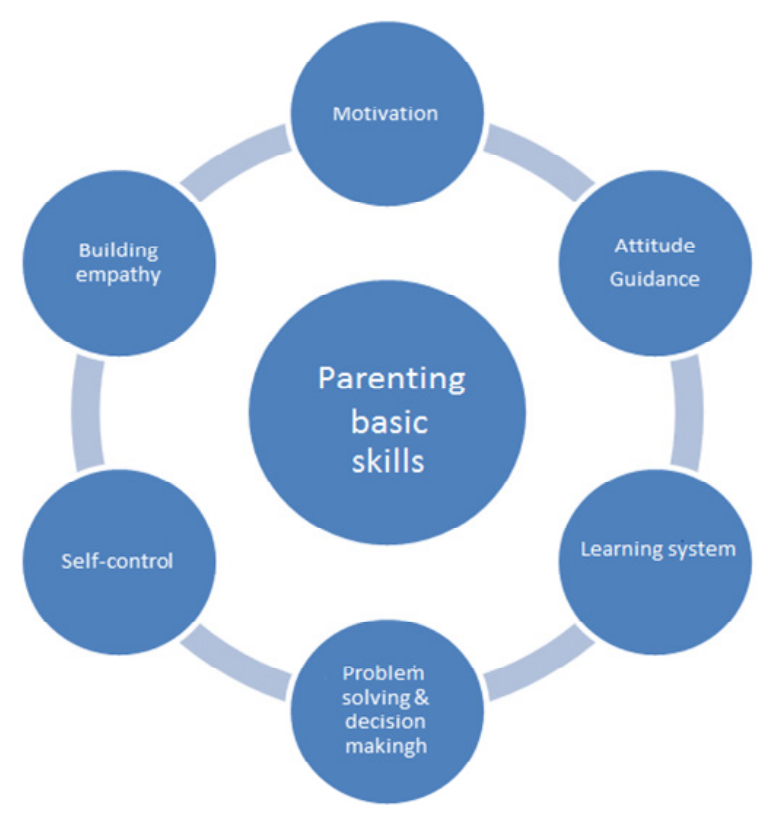

Figure 2. The curriculum of the parenting training program

Based on the Figure 2, it is shown that parents had to have basic skills in parenting. The basic skills included: (1) self-awareness of the importance of teaching their children. The awareness was not only necessarily to focus on the aims, but also it could contribute to the basic changes. The changes could only happen if there was any awareness from the parents. This awareness was one of the elements that were needed to keep the parents motivated. By having enough awareness, the parents would have some spirit to change their paradigm, attitude, and beliefs. (2) Attitude mentoring would be realized when parents understood the importance of teaching children from their young. (3) Problem solving and decision making were also important. By using this basic skill, certain problems could possibly have potentials; either they would give disadvantage or giving much advantage. Thus, problem solving meant responding to a problem so that its bad effect could be reduced and the benefits could be maximized. The importance of the problem solving was not based on the amount of time needed, but more on its consequence. Meanwhile, decision making meant choosing strategies or actions that were believed would give the best solutions to solve the problem. One of the successful key of problem solving was identifying all the decision alternatives. The best solution had to be able to empower the system to meet its goal, (4) self-control from parents was needed so that the children's attitude, growth, development, and health would be well-controlled, (5) building empathy to fill the basic skill in the parenting activities.

The parenting training used a transformative learning approach. The transformative learning was the ultimate theory in teaching an education philosophy. Applying the transformative learning in the parenting training was not an easy matter because it needed changes and self-reflection from the parents. Therefore, to meet the expected result, parents were insisted to have jobs, skills, and courage.

The training model that was developed in the parenting training had to be able to make transformation (changes). The change should have been substantial, it meant parents who made transformation could be identified that they learned something. Yet when they did not happen to change in terms of mindset, perception, paradigm, personality, or belief; it meant that they only experienced the learning process - but not the transformative one (Moedzakir, 2010). The figure below is the diagram of transformative approach used in the parenting training model. 

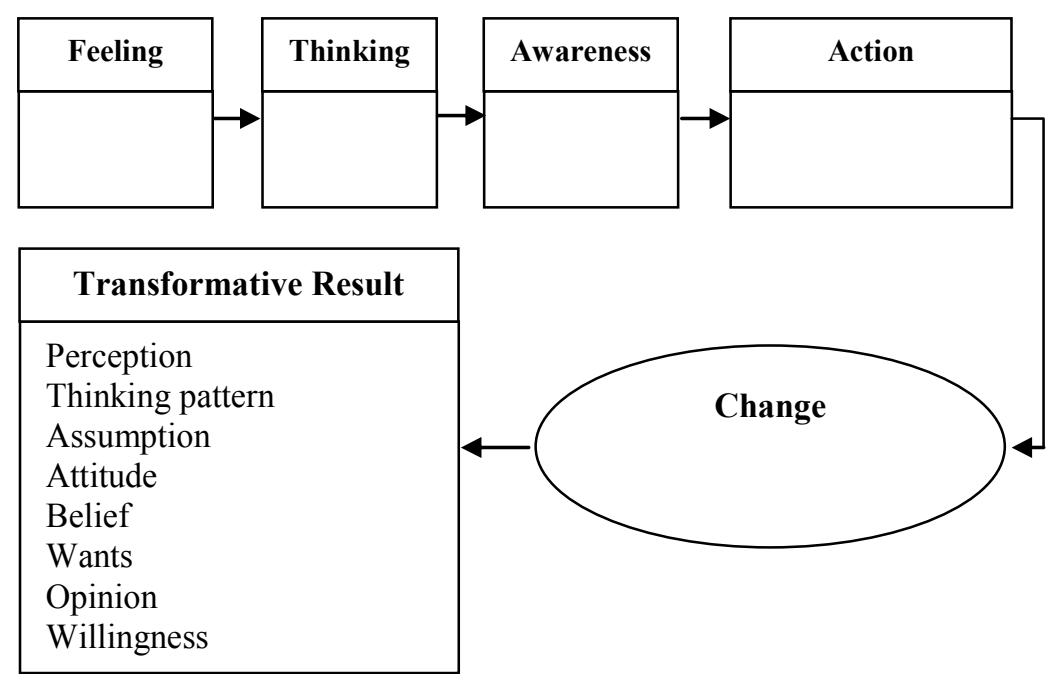

Figure 3. Transformative approach used in the parenting training model

To meet the objective of the parenting training program of the character education for the poor families through the transformative learning approach, there were some elements that had to be concerned. First, content. It meant that the content in the parenting training had to focus on the participants' needs, trigger the participants to be actively involved in the training, trigger them to express their idea of how to build good attitude of their children, and grow the cooperation among the participants and the trainers. Without the good cooperation, the goal of the training would not be achieved. Therefore, the trainers should have not only delivered materials, but they were also expected to share information with the training participants. This was because parents had a lot of experiences in raising their children, but they just never had a chance to discuss and sharing their strategies to other people.

To develop the parenting training model, the trainers should have understood the problems faced by most parents. During the training, mentors were needed to be responsible to the training process. The mentors were expected to be able to develop empathy, have respect, commit to present in the training, never cut the talk, never argue, and not to discriminative.

The parenting training with the transformative learning approach was expected to be able to solve the problems of parenting. The mechanism used in the parenting training was andragogy as the science and art of teaching adults in learning. Consequently, the way to teach the parents in the training was totally different with teaching children.

Some methods applied in the parenting training with the transformative learning approach were lectures, discussions, field observations, and practices. To make the training easier to conduct, some media were needed, i.e. pieces of information (leaflets, brochures, and posters), audio visual media (VCD, radio, television, projector, and films), and collection of news from the printed media, books, and some other media.

The material for the parenting training was suited with the condition and problems faced by the parents. The major themes discussed in the training were improving the health, health maintenance, nursing, nurturing, education, and protection.

In conducting a parenting training, it was needed to involve the PAUD (Pendidikan Anak Usia Dini or Early Childhood Education) to bridge the training program. The role of the PAUD was providing a training place and meeting facilities that were suitable with the condition and needs of the parents, allocating time, arranging training activities, publishing the training information, and recommending names of trainers.

The main target in the parenting training was parents. But there were also some people involved in the training, e.g. (1) parents whose children went to PAUD (TK, KB, TPA, Pos PAUD, etc.), (2) parents whose children had not studied at PAUD yet, and (3) soon-to-be parents and other parties who were interested to join the training. 


\section{Discussion}

The approach applied in the parenting training which required the active participation from the parents in parenting was based on these aspects. First, development of the moral and religion values had to go continuously, so that children could realize the values and they could develop the emotional skill and independence. Second, the teaching should have done in the exciting atmosphere by using strategies, materials, and media that were easily understood by the children. Next, the teaching was oriented to the children's development so that it was important to give activities that were suitable with their stage of development. Moreover, the learning activities should have always been oriented to the children's need, in which the activities were based on the children's development. Fifth, the learning used thematic approach as the introductory concept of self-recognition. Furthermore, the learning activities should have been active creative, effective, and exciting. Seventh, the learning activities should have taught the life skills. Last, the learning activities should have been meaningful to stimulate the children's potential so that it was necessary to use natural materials, synthetic materials, and learning materials from the environment provided by the teachers.

This nurturing model was provided as an enrichment of parenting method that had been applied by parents. The enrichment was in the form of study cases, such as how to handle the problems related to nurture children and how to educate children well. In general, the strategy applied in this model of parenting was (1) focusing on the parents' needs, (2) triggering parents to be active and curious, (3) making parents use their daily experience to educate their children well, (4) growing cooperation and improving self-quality and family's quality independently, (5) sharing information, not only transforming knowledge, (6) motivating parents to raise their children well, and (7) empowering through outsiders.

The introduction was done in a democratic way, regarding to the fact that PAUD was the subject in the learning process. It made the children able to interact well, both with the education system and their peers in some ways; (1) learning by doing, in which the learning activity was done directly by children, (2) learning by stimulating, in which the learning activity was focused on how to stimulate children's development, (3) learning by modelling, in which children imitated adults and peers around them.

It was necessary to give parents some knowledge related to the psychological aspects and moral values. Thus, parents should have had some basic skills in parenting, such as: (1) self-motivation to change their mindset so that they could be more aware of the importance of educating their children well, (2) guidance towards attitude would be realized when parents understood the importance of educating their children since they were in the early age, (3) problem solving and decision making, (4) parents' self-controlling would make the children's attitude, growth, development, and health went well, and (5) strong empathy was needed as the modal of basic skill in parenting activities.

\section{Conclusion}

There were some obstacles faced by parents in giving character education to their children. First, parents had to be able to become the role model for their children. Second, parents should comprehensively understand the importance of character education so that they can raise their children well. Next, most parents expect that the parenting training models is more practical than theoretical. Another thing that needs to be highlighted is the parenting training program should involve many elements, like PAUD, parents, and community leaders and it is expected to make a prototype of parenting training. Moreover, to make the prototype, it is needed to do some identification related to the parents' understanding towards the parenting, the needs in the training, description of the expected training, exploration of the strength and weakness of the parenting model, and analysis.

\section{Acknowledgments}

The researcher to thank Dean of Faculty of Education of State University of Malang and also to thank Dr. Nasikh as Senior Lecturer in Faculty of Economics, Universitas Negeri Malang who had helpfull discussion and help preparation of the article.

\section{References}

Aziz, H. A. (2011). Character Education at Heart: Good Morality as the Foundation to Build Nation's Characters. Jakarta: Al-Mawardi Prima.

Baumrind, D. (2006). Effects of Authoritative Parental Control on Child Behavior. Child Development, 37(4), 887-907.

Borg, Walter. R., \& Gall, M. D. (2005). Educational Research: An Introduction (3rd ed.). New York: Longman.

Fanning. (2007). Parent training for caregivers of typically developing, economically disadvantaged 
preschoolers: An initial study in enhancing language development, avoiding behavior problems, and regulating family stress (Dissertation, Oregon University Press).

Gupta, L. (2008). A comparison of parenting behavior between European American and Asian Indian parents (Dissertation, University of Arkansas).

Jarvis, P. (2004). Adult Education and LifeLong Learning. Theory and Practice (3rd ed.). London \& NewYork: Roudledge Falmer.

Kamil, M. (2010). The Model of Teaching and Training. Bandung: Alfabeta Publishing.

Marzuki, M. S. (2009). Dimensions of Non formal Education. Malang: Faculty of Education State University of Malang.

Mezirow, J. (2003). Epitemology of Transformative Learning.

Moedzakir, M. D. (2010). Teaching Method to Outside School Programs. Malang: UM Press.

State University of Malang. (2010). Guidelines to Writing Scientific Papers: Undergraduate Thesis, Thesis, Dissertation, Articles, Papers, Final Assignment, Research Report. Malang: State University of Malang.

Taylor, E. W. (2007). An Update of Transformative Learning Theory: A Critical Review of the Empirical Research (1999-2005). International Journal of Lifelong Education, 26(2), 173-191. http://dx.doi.org/10.1080/02601370701219475

Wibowo, T. (2011). The Role of Parenting in Building Children's Characters. Retrieved December 6, 2013, from http://www.pendidikankarakter.com/peran-pola-asuh-dalam-membentuk-karakter-anak/

\section{Copyrights}

Copyright for this article is retained by the author(s), with first publication rights granted to the journal.

This is an open-access article distributed under the terms and conditions of the Creative Commons Attribution license (http://creativecommons.org/licenses/by/3.0/). 